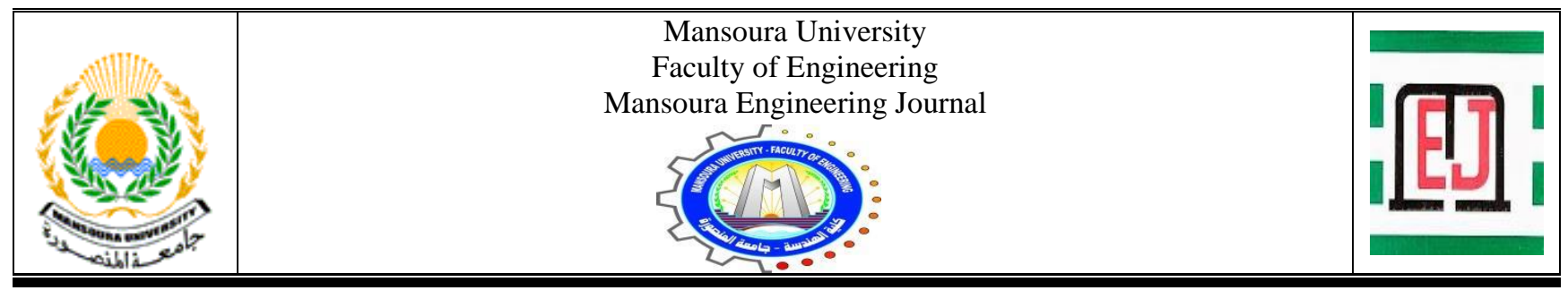

\title{
Enhancement of Heat Transfer for Electronic Components in Horizontal Channel by Passive Cooling
}

\author{
M.I. Salem*, G.I. Sultan, A.A. Hegazi, and Waleed M. ElAwady
}

\begin{abstract}
KEYWORDS:
Enhancement of heat transfer, Perforated holes, Passive cooling, mixed convection, $C F D$ simulation, Electronic cooling.
\end{abstract}

\begin{abstract}
In this study, numerical investigation on heat transfer by mixed convection for air-cooling through a rectangular horizontal duct with three heat sources is conducted. These heat sources are rectangular ribs with different small aspect ratios and every heat source emits uniform heat flux with small space between each other. The investigation is to enhance forced convection that produced from fan through a rectangular horizontal duct with natural convection using perforated holes between each heat source. The study shows the effect of air entering through the holes at different open hole ratio $\beta(0.01472,0.02618,0.04091,0.05891,0.08017)$ and with Reynolds number $\mathrm{Re}$ in the range $(376,900,2073,3428$ and 6170) and at Grashof number $\mathrm{Gr}=0.371 \times 10^{7}$ on the temperature of each heat source. The results show the best performance at open hole ratio 0.04091 for which the dimensionless temperature decreased by $5 \%$ for the first heater, $15 \%$ for the second one and $6 \%$ for the third one.
\end{abstract}

\section{INTRODUCTION}

$\underline{\square}$ lectronic components in those days have very important role in the progress of our technology and has a major usage in large amount of processes in our daily life. Those electronic components consist of very small elements that generate heat and to keep it works at best performance for as long as possible the amount of heat should not excess to limitations that can encrypt the processing. For the previous purpose, cooling these components is very important, the most common system for this cooling is to flow the air through electronic chips in their rectangular ducts to remove heat by forced convection, Incropera [1]. The major direction these days is to minimize the size of electronic chips

Received: (21 January, 2021) - Revised: (4 April, 2021) - Accepted: (05 May, 2021)

* Corresponding Author: M. I. Salem, Assistant teacher at Future Institute, Mansoura, Egypt (email: mohammedsallem77@gmail.com).

G. I. Sultan, Professor at Mechanical Power Engineering Department, Mansoura University, Mansoura, Egypt (email: gisultan@mans.edu.eg).

A. A. Hegazi, Associate Professor at Mechanical Power Engineering Department, Mansoura University, Mansoura, Egypt (email: ahmedabd_elsallam@yahoo.com).

Waleed M. ElAwady, Assistant Professor at Mechanical Power Engineering Department, Mansoura University, Mansoura, Egypt (email: welawady@mans.edu.eg). for which the board can use a large number of chips and large number of functions can be made, for that, the cooling process became a vital process for these chips. We have two major ways for cooling active and passive, passive one is the way for which you do not need any outsource energy forenhancement the transfer of heat for cooling.

\section{LITERATURE REVIEW}

There are many efforts in this field for which we can build up our study to improve the progress of the work in cooling electronic chips. Chang et al. [2] investigated experimental work about heat transfer in a rectangular channel fitted enhancement of heat transfer roughness with V-shaped ribs. They made a flow backward and forward using that in turbulent and laminar regime, their results point to HTE (heat transfer enhancement) ratio for test channel with forward and backward flows, respectively, reach 9.5-13.6 and 9-12.3 for laminar flows and 6.8-6.3 and 5.7-4.3 for turbulent one.

Buchlin [3] investigated an experimental study on heat transfer by convection in a horizontal channel with perforated ribs, effect of rib design on heat transfer, and effect of rib-torib spacing. The open area ratio with different Reynolds numbers for the channel. Compared to solid rib, a local thermal enhancement factor of three can expect just behind the perforated tabulator. Chandra et al. [4] performed an experimental study of turbulent flow air in a square channel 


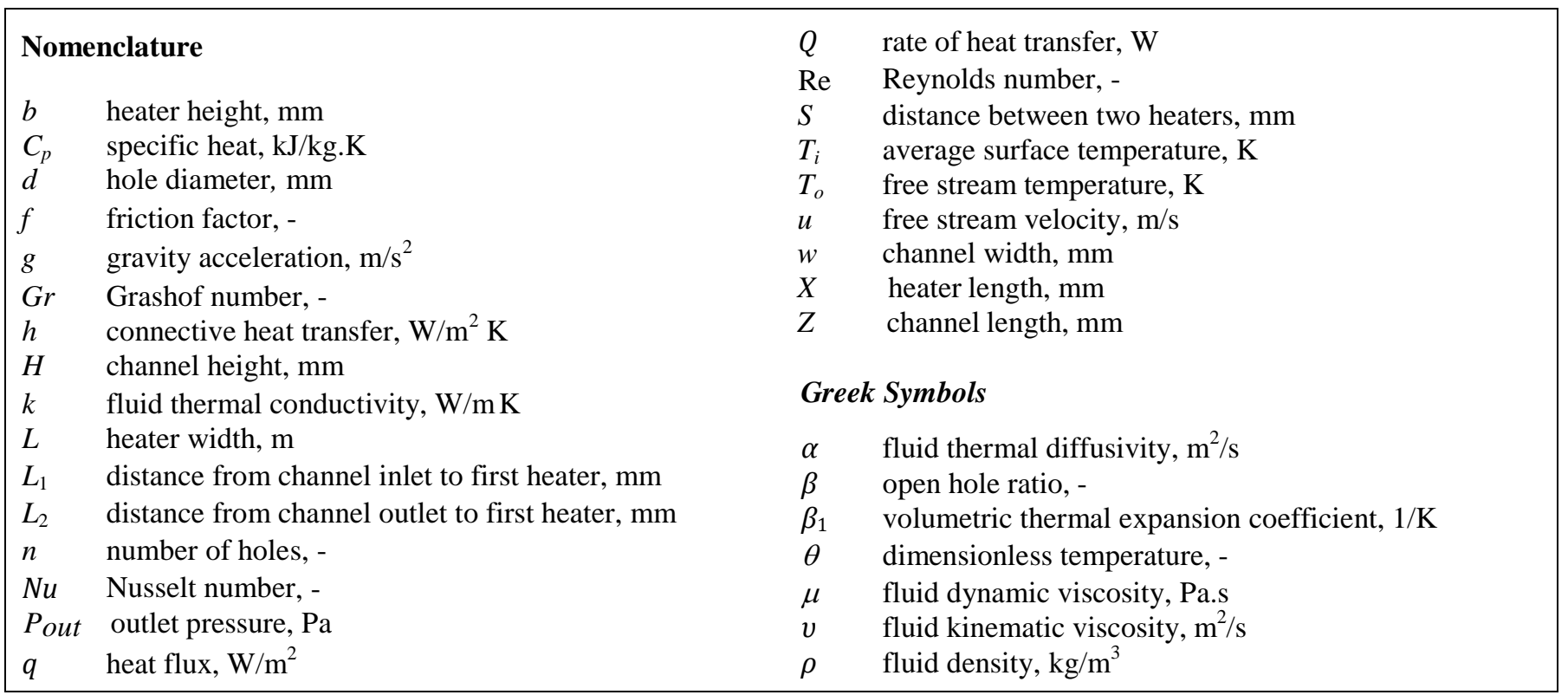

with transverse ribs and its effect on the surface heat transfer and friction characteristics. The results indicate that the heat transfer coefficient and friction factors increased with the number of ribbed walls.

Lau et al. [5] conducted an experimental study for heat transfer enhancement by blockages with holes (square and round) that are in staggered arrangement for turbulent airflow. The result shows that these blockages enhancing heat transfer coefficient for fully developed turbulent flow through smooth channel by 4.7-6.3 times. Sara et al. [6] represented an experimental investigation on the enhancement of heat transfer and its corresponding pressure drop over flat surface in channel due to ribs, which is in rectangular cross section shape. The study deduced new correlations for calculation of Nusselt number and they can save up to $40 \%$ of the energy using this perforation.

Dutta and Hossain [7] made an experimental study that investigates the effect of inclined perforated ribs in a horizontal channel on the local heat transfer coefficient and friction loss. They used flow with the Reynolds number range between 12,000 and 41,000. This study proved that the heat transfer coefficient strongly depends on the geometry, orientation, shape of the ribs in the horizontal duct. Sultan [8] conducted experiments for enhancing forced convection for cooling three heat sources in a horizontal rectangular duct. Perforated holes between each heat source is used for make natural convection due to the pressure difference between holes, the study flow regime is turbulent and using different open hole ratio.

Ali [9] made an experimental study for the enhancement of heat transfer using cooling by perforated holes in two lines between each heat source. It was noticed that the average Nusselt increased by using the perforation in the duct and reduced the temperature of the heat source of the module. Ali et al. [10] investigated a numerical study for the effect of the space between the electronic components on the heat transfer coefficient using ANSYS FLUENT. The results explained that the temperature can decrease with spacing ratio until it reaches 3 then the spacing effect can be neglected.
Ghasemi and Aminossadati [11] investigated a twodimensional numerical study to thermal and physical model of forced convection heat transfer from individual heat sources. Their results deduced that the thermal distribution relies on the amount of heat sources was in the duct and the arrangement. Alves and Altemani [12] deducted the effect of flow convection in laminar case on average Nusselt numbers for three heat sources mounted on a wall that has parallel plates in the channel to develop the required flow. A numerical procedure constructed for the calculation of the coefficient of convective heat transfer to every heat source mounted on the wall.

El Nakla [13] studied the effects of the height and the width of the rib, the space between each rib and the distribution of heat flux change of the elements on the average Nusselt number and coefficient of heat transfer. The study used a commercial CFD package in two dimensions. Results show that the thermal performance has a great relation with the geometry of heat sources and its characteristics. Zeng and Vafai [14] numerically investigated for the velocity flow, the ratio of lengths between clearance height and rib length, the ratio of lengths between rib spacing and channel height, blocks geometric ratio, and total amount of ribs effects on the cooling by forced convection.

Jassim and Muzychka [15] found that the distribution of heat sources installed on the wall in non-uniformed way can give an optimized model for the distribution of heat transfer by forced convection regardless of the geometric properties with free stream velocity and improve the effectiveness of the processes by reducing the heat sources right after the leading edge. Mathew and Hotta [16] made an experimental study that investigates the orientation of IC chips for the laminar forced convection flow. The aim of the study is to know the optimum configuration for IC chips mounted on the board. The study deduced that the temperature of IC chips is maximum for the vertical board. Air velocity is also important for the cooling of the IC chips. 


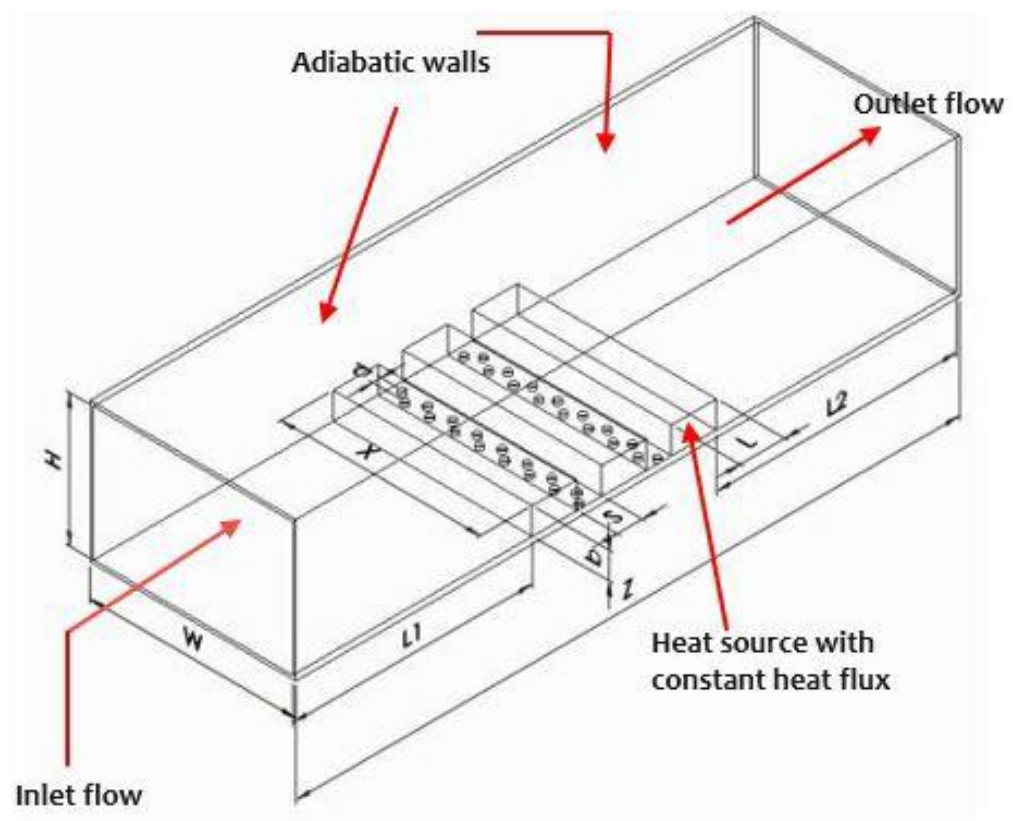

Fig. 1 Schematic diagram of duct design

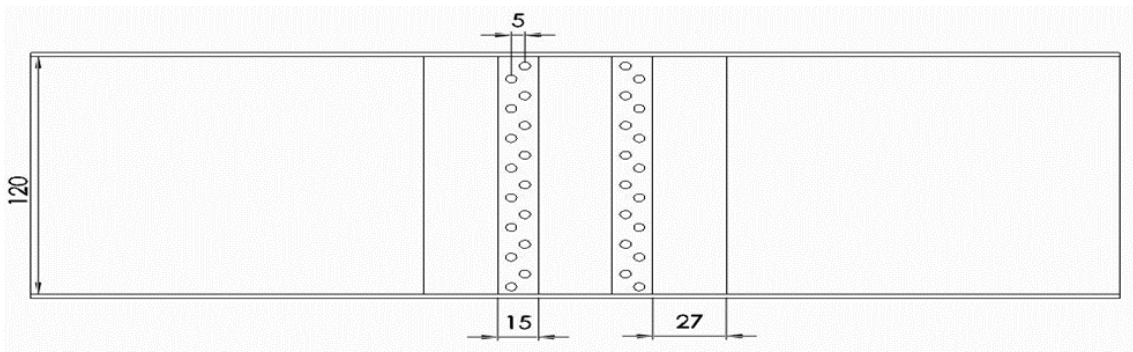

Fig. 2 Schematic for heat sources with holes

da Silva et al. [17] deduced a comparison between numerical and experimental investigation to study the effect of the spacing between heat sources for how it has a great relation and effect on the thermal performance. The study represented an optimal distribution to the position of individual heat sources to give the best cooling performance by the forced convection made by the external source. Alamgholilou and Esmaeilzadeh [18] studied experimentally the effect of perforated holes between the heat sources and compared between the holes arrangement in centered space between heat sources and near the wall of heat sources.

Jubran and Al-Haroun [19] investigated experimentally injection mechanism for entering air through holes in perforation between heat sources, the study deduced the cooling enhancing with reducing the injection mechanism angle. Cheng et al. [20] studied numerically the effect of openings in plate between heat sources, the study deduced that openings could lower maximum temperature of heat sources and increasing Nusselt number.

Deng et al. [21] studied numerically the effect of the separation distance ratio. The study concluded that when the ratio is larger than one, the flow induced upward between heat sources and this decreases the temperature of the heat sources.

In this study, the numerical investigation for the effect of the open hole ratio to the enhancement of cooling for the heat sources was conducted and also study the effect of different arrangement (staggered/inline) of the holes on the temperature of heat sources and on the Nusselt number.

\section{MATHEMATICAL FORMULATION}

The schematic diagram of the three-dimensional physical model that shown in Figures 1 and 2, the cad design is built up using the dimensions of the experimental apparatus. The length of the duct is $(Z) 600 \mathrm{~mm}$ with rectangular cross section area inlet. The duct is made of wood with three heaters made of aluminum. The distance between first heater $L_{1}=200 \mathrm{~mm}$ and distance between the third heater and outlet $L_{2}=200 \mathrm{~mm}$. The dimensions of the heater are $120 \mathrm{~mm}$ long $(X), 16 \mathrm{~mm}$ height $(b)$, and $27 \mathrm{~mm}$ wide $(L)$. The distance between each two-heat sources is $15 \mathrm{~mm}(S)$, there are 16 holes between each heat source and the distance between two holes is $5 \mathrm{~mm}$ apart.

The open hole area ratio $\beta$ is the ratio of the total area of the holes to the area of the side of the heater:

$$
\beta=1-\frac{n(\pi / 4) d^{2}}{w b}
$$

The result is represented as a parameter of the dimensionless temperature $(\theta)$, Reynolds number (Re), and Nusselt number $(\mathrm{Nu})$ as:

$$
\begin{aligned}
& \theta=\left(T_{i}-T_{o}\right) /(q L / k) \\
& \operatorname{Re}=u L / v
\end{aligned}
$$




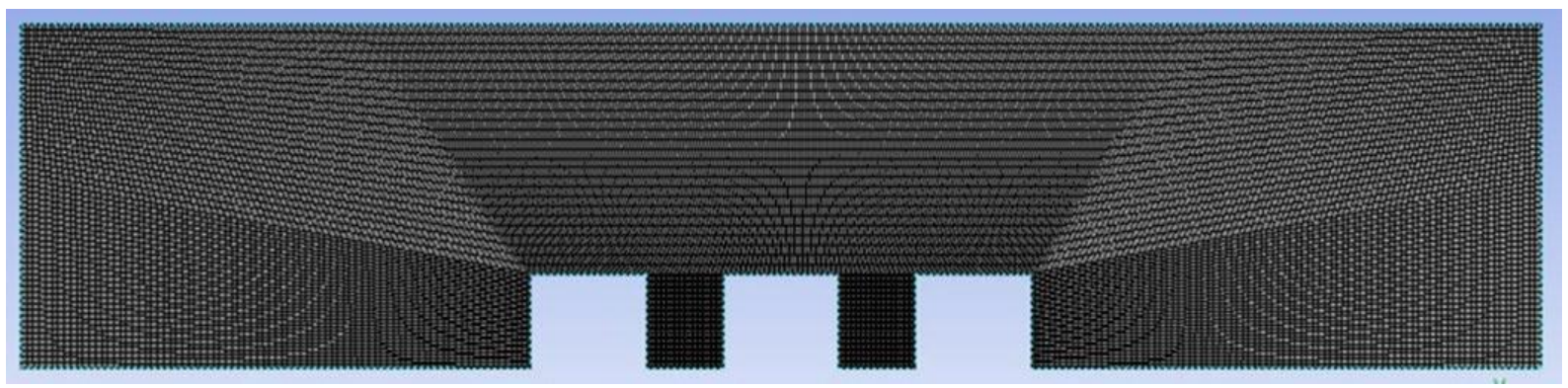

Fig. 3 Schematic for no holes mesh grid

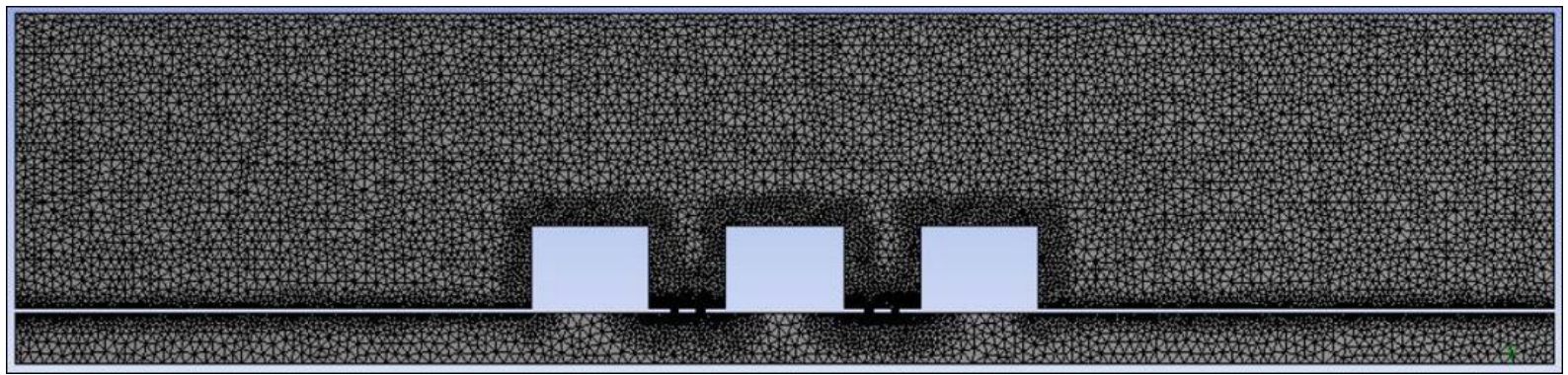

Fig. 4 Schematic for holes mesh grid

$$
N u=q L / k\left(T_{i}-T_{o}\right)
$$

and the Grashof number is represented as follows:

$$
G r=g \beta_{1} q(L+2 b) L^{3} / k v^{2}
$$

The improvement percentage represents the ratio of the enhancement in Nusselt to friction factor percentage.

$$
\text { improvement }=\frac{\left(\frac{N u}{N u_{o}}\right)}{\left(\frac{f}{f_{o}}\right)^{1 / 3}}
$$

The subscript $o$ represents no holes case.

The following assumptions made for the model:

1- Three-dimensional

2- Uniform heat flux for each heat source

3- Uniform velocity inlet

4- Turbulent flow

5- Steady state

6- Neglect irradiative heat transfer

The governing equations of mass, momentum, and energyconservation written as:

(1) Continuity equation

$$
\frac{D \rho}{D t}+\rho \frac{\partial U}{\partial x_{i}}=0
$$

(2) Momentum equation

$$
\rho \frac{\partial U_{j}}{\partial t}+\rho U_{i} \frac{\partial U_{j}}{\partial x_{i}}=-\frac{\partial P}{\partial x_{i}}-\frac{\partial \tau_{i j}}{\partial x_{i}}+\rho g_{j}
$$

(3) Energy equation

$$
\rho c_{\mu} \frac{\partial T}{\partial t}+\rho c_{\mu} U_{i} \frac{\partial T}{\partial x_{i}}=-P \frac{\partial U_{i}}{\partial x_{i}}+\gamma \frac{\partial^{2} T}{\partial x^{2}}-\tau_{i j} \frac{\partial U_{j}}{\partial x_{i}} \text { (9) }
$$

To solve numerically the previous governing equations, the boundary conditions related to the geometry given by Fig. 1 must be defined. These conditions consist of flow conditions and thermal conditions as shown in Table (1). The properties of aluminum, wood, and air are given in Table (2).

\section{TABLE (1)}

FLOW AND THERMAL BOUNDARY CONDITIONS

\begin{tabular}{c||c||c||c} 
Boundary & Velocity & Temperature & Pressure \\
\hline \multirow{2}{*}{ Inlet } & $\begin{array}{c}\mathrm{u}=\mathrm{u}_{\mathrm{n}} \\
\mathrm{v}=0 \\
\mathrm{w}=0\end{array}$ & $\mathrm{~T}_{\mathrm{i}}=298 \mathrm{~K}$ & \\
\hline Outlet & & & Pout $=$ Patm \\
\hline Wall & $\begin{array}{c}\mathrm{u}=\mathrm{v}=\mathrm{w}=0 \\
\text { (viscous flow) }\end{array}$ & $\begin{array}{c}\mathrm{Q}=0 \\
\text { (adiabatic wall) }\end{array}$ &
\end{tabular}

TABLE (2)

PROPERTIES OF ALUMINUM, WOOD, AND AIR USED

\begin{tabular}{l||c||c||c||c||c} 
Material & $\begin{array}{c}\boldsymbol{k} \\
(\mathbf{W} / \mathbf{m} . \mathbf{K})\end{array}$ & $\begin{array}{c}\boldsymbol{\rho} \\
\left(\mathbf{k g} / \mathbf{m}^{\mathbf{3}}\right)\end{array}$ & $\begin{array}{c}\boldsymbol{C}_{\boldsymbol{p}} \\
(\mathbf{J} / \mathbf{k g . K})\end{array}$ & $\begin{array}{c}\boldsymbol{\mu} \\
(\mathbf{P a . s})\end{array}$ & $\begin{array}{c}\boldsymbol{\alpha} \\
\left(\mathbf{m}^{2} / \mathbf{s}\right)\end{array}$ \\
\hline Aluminum & 202.4 & 2719 & 871 & - & - \\
\hline Wood & 0.173 & 700 & 2310 & - & - \\
\hline Air & 0.0242 & 1.225 & 1006.43 & $1.7894 \mathrm{e}-05$ & 0.0034
\end{tabular}

\section{NUMERICAL COMPUTATIONS}

The numerical simulation is performed using Fluent 18.1, the generated mesh grid in case A (no holes) contains $(1,642,016)$ cells and case B contains $(4,107,716)$ (holes) cells as shown in Fig. 3 and Fig. 4, respectively. The mesh grid tests made for the change of temperature of the three heat sources with the number of mesh cells are shown in Figs. 5, 6, and 7. The turbulence model used in our case is the $\mathrm{k}-\varepsilon$ model, the 


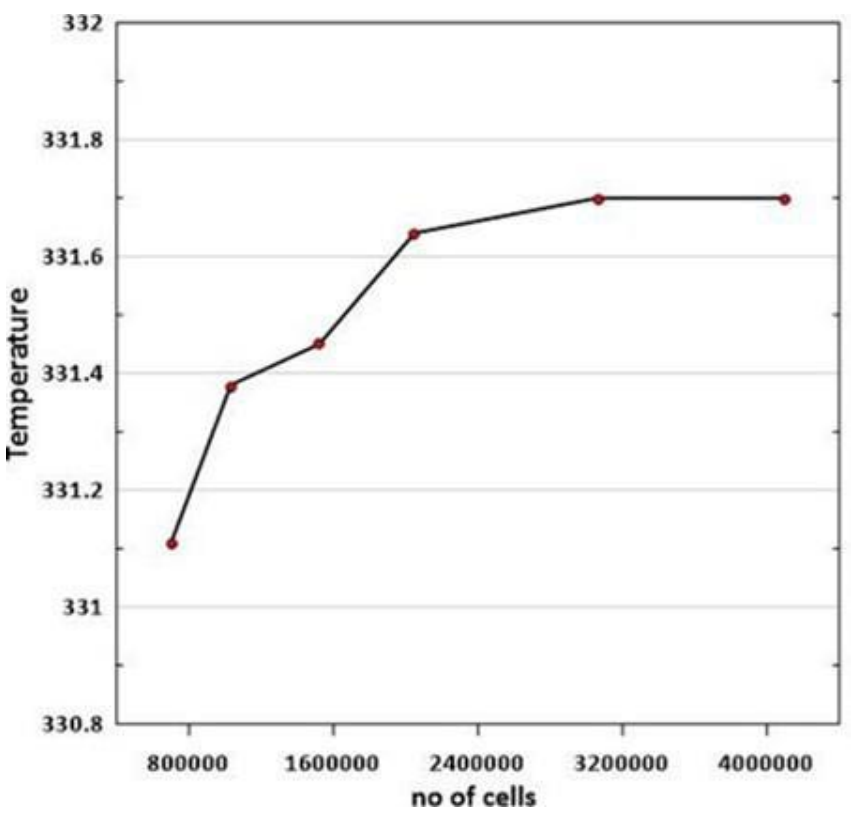

Fig. 5 Schematic mesh grid test for first heater

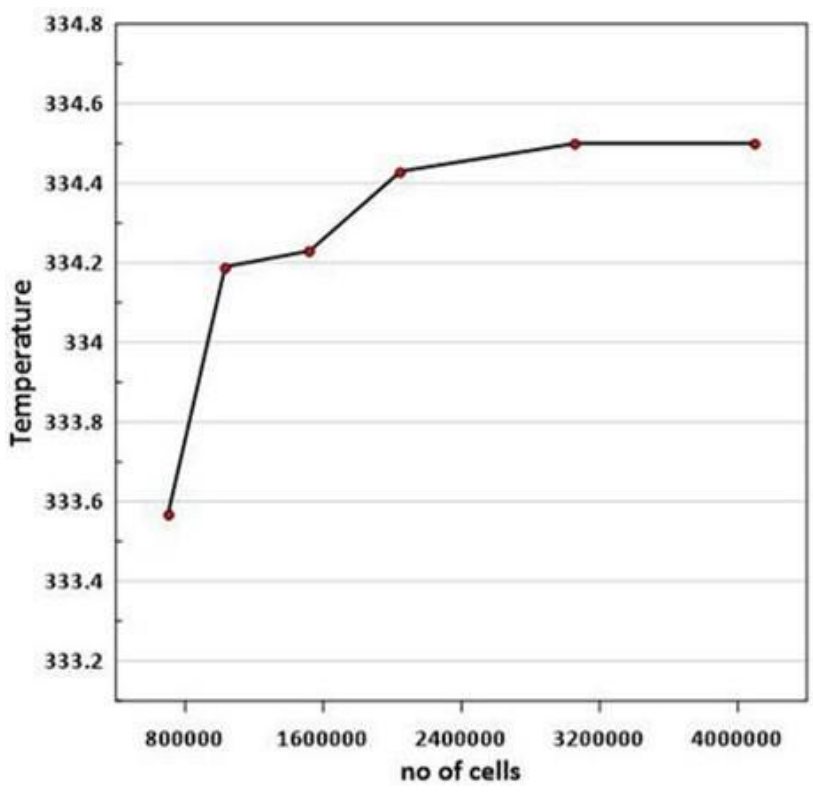

Fig. 7 Schematic mesh grid test for third heater

convergence criteria for momentum equation parameters is $10^{-4}$ and for energy and continuity equations is $10^{-5}$. The threedimensional Navier-Stokes and energy equations are solved numerically by a finite-difference scheme.

The continuity and momentum equations calculated with high concentration on nodes in regions are highly unstable process. Different sizes for mesh cell and size, which no temperature change with the previous one is the size used in the calculations.

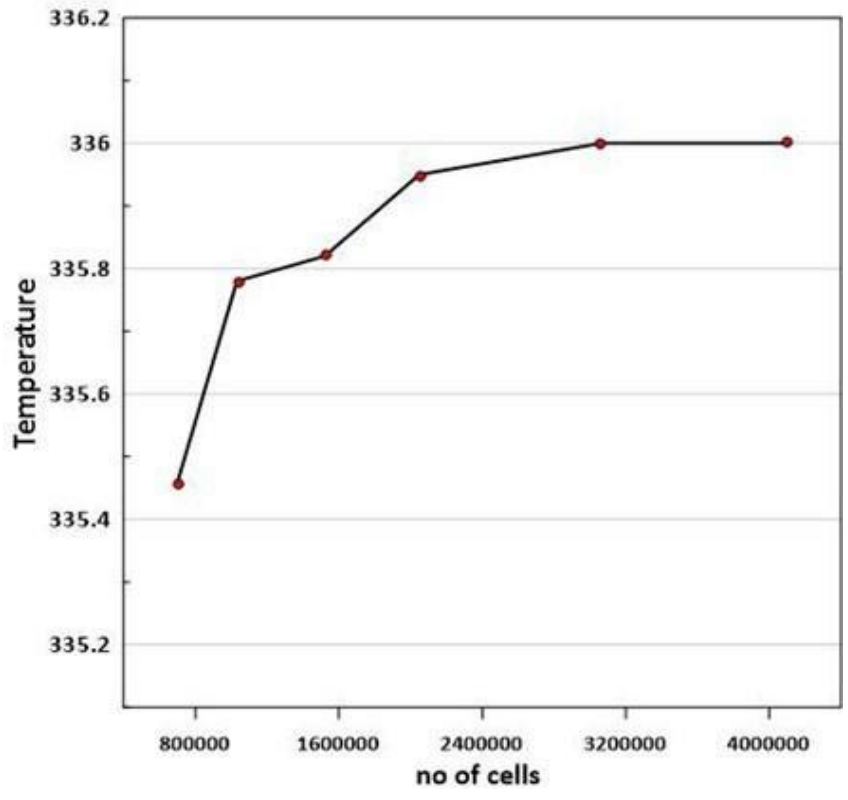

Fig. 6 Schematic mesh grid test for second heater

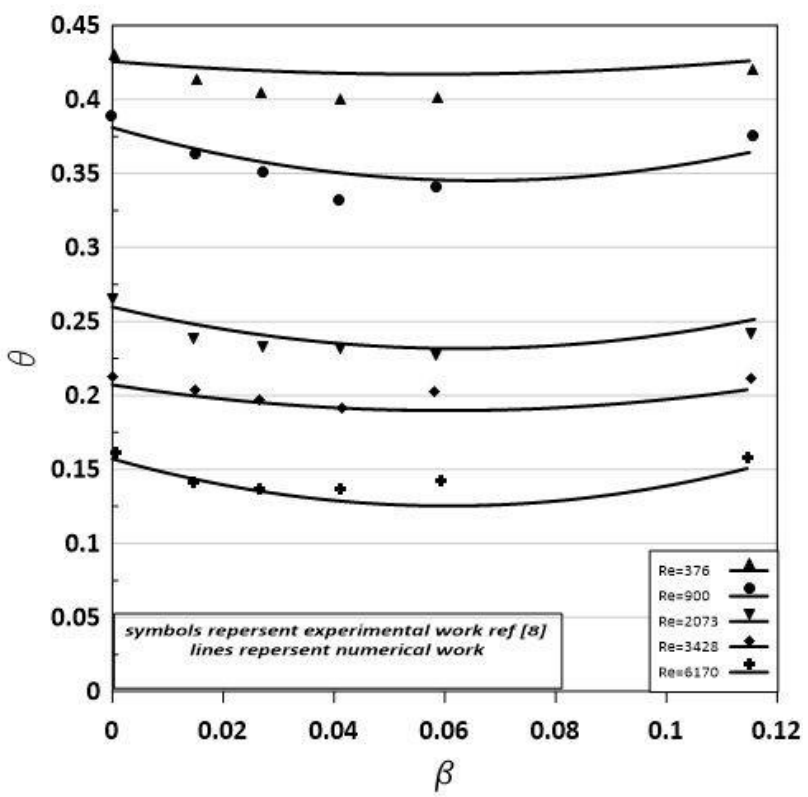

Fig. 8 First heater dimensionless temperature variation with open hole ratio for numerical and experimental works

\section{RESULTS AND DISCUSSION}

The distribution of dimensionless temperature along the duct of the surfaces of the heaters at different open hole ratio $\beta$ $(0.01472,0.02618,0.04091,0.05891$ and 0.08017$), \mathrm{Re}$ in the range $(376,900,2073,3428$ and 6170) and at Grashof number $G r=0.371 \times 10^{7}$.

The dimensionless temperature reduces with open hole gradually until a value of $d=2.5 \mathrm{~mm}$ then increases as shown in Figs. 8-10. The flow separation after each heat source forms a wake region of low pressure and due to the pressure gradient, buoyancy effect forces the air streamline to flow through holes and carry out heat from the sides of the heat sources. 


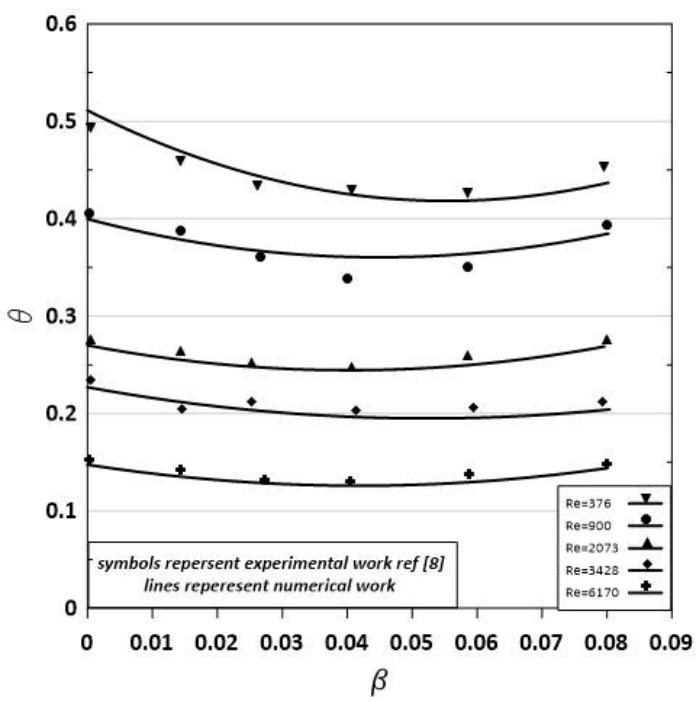

Fig. 9 Second heater dimensionless temperature variation with open hole ratio for numerical and experimental works

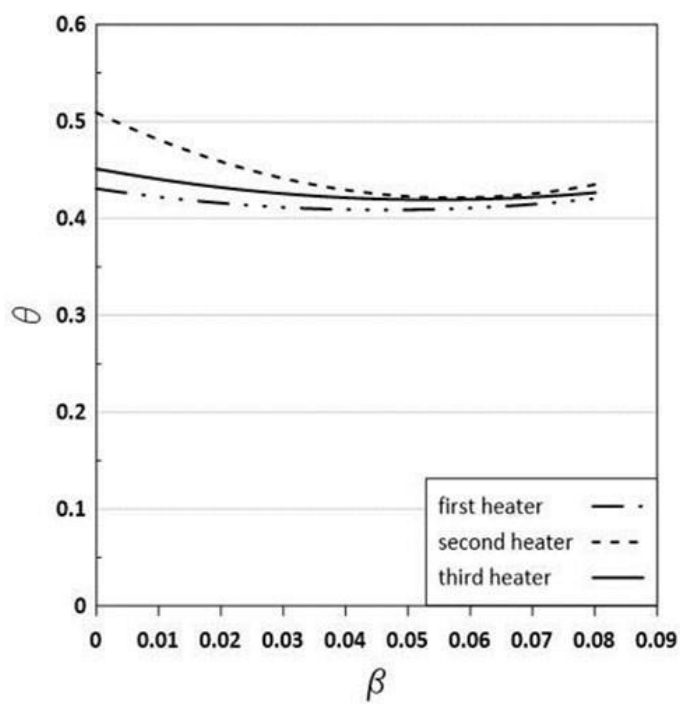

Fig. 11 Dimensionless temperature comparison between the three heaters with open hole ratio at $\mathrm{Re}=376$

There are two major factors that affect the flow pressure drop: the friction pressure drop as the air flows through holes and the pressure drop of recirculated air momentum. The friction pressure drop is inversely proportional to the hole diameter. On the contrast, the momentum pressure drop is directly proportional to the hole diameter. So, the velocity of the cold air induced between heat sources increases gradually until certain value then decreases.

The average deviation percentage between the present numerical results and literature experimental results for the first heater is $3 \%$, for the second one is $2.6 \%$, and for the third heater is $3.1 \%$.

The dimensionless temperature distribution at $\mathrm{Re}=376$ for the second heater is larger than the other heaters and this difference decreases gradually with increasing the diameter of the hole as shown in Fig. 11, otherwise at $\mathrm{Re}=6170$, the second heater is larger than the first one and less than the third heater as shown in Fig. 12.

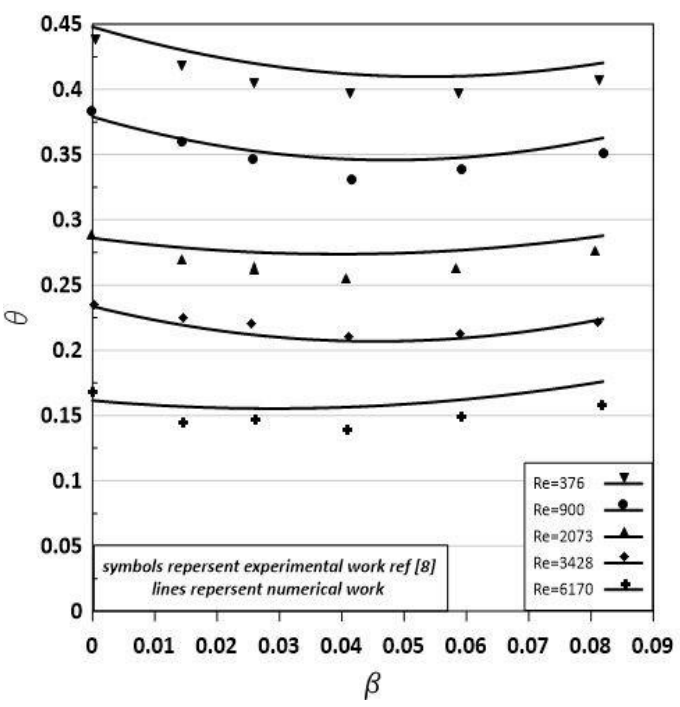

Fig. 10 Third heater dimensionless temperature variation with open hole ratio for numerical and experimental works

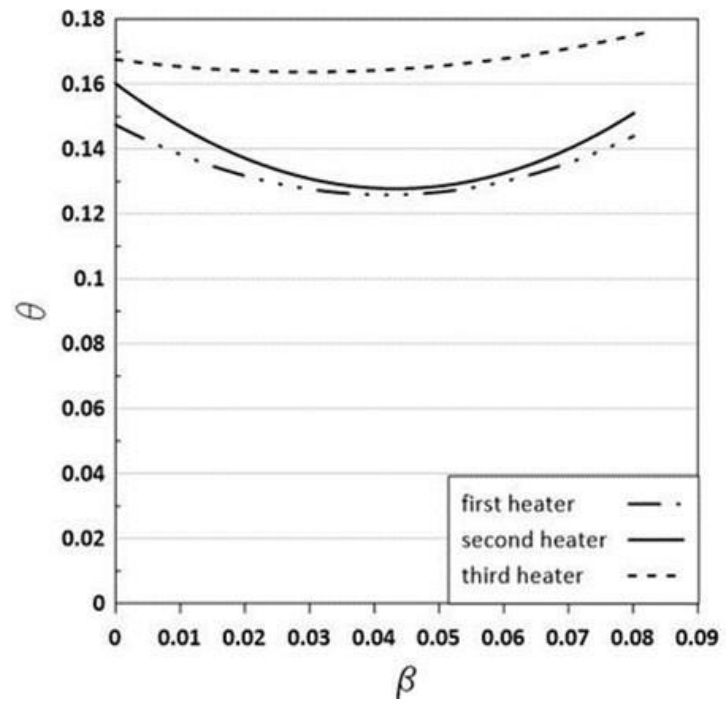

Fig. 12 Dimensionless temperature comparison between the three heaters with open hole ratio at $\mathrm{Re}=6170$

To explain this, we need to know that there are two types of cooling in our case; forced convection cooling due to the fan in front of the duct and natural convection due to the holes between the heat sources and the pressure gradient.

For low Reynolds number, the natural convection effect is larger than the forced convection effect, and for high Reynolds number, the forced convection is the dominating factor.

There is no doubt that duct with holes gives cooling better than no-holes one, due to the effect of enhancing cooling of forced convection in addition to the buoyancy effect.

In all cases, the temperature of the first heater is less than that of the other heaters because it receives fresh cold air from the inlet of the duct directly, then the adjacent air carries out heat from the surface of the first heater then heated air passes to the surfaces of other heaters.

The arrangement between heat sources plays major role in enhancing cooling, and inline arrangement also detected with staggered one. It is noticed that the dimensionless temperature of heat sources in staggered arrangement is less than inline one 


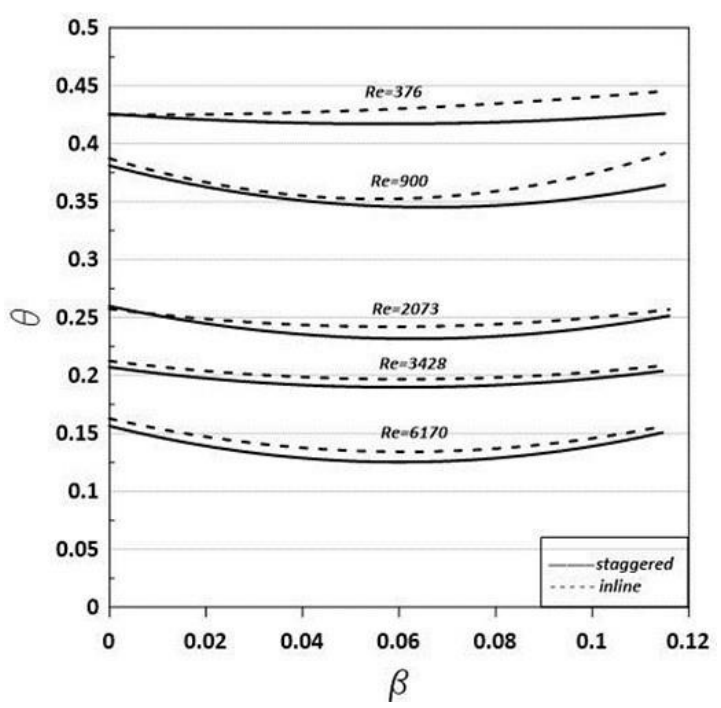

Fig. 13 Dimensionless temperature of first heater variation with open hole ratio for staggered and inlinearrangements

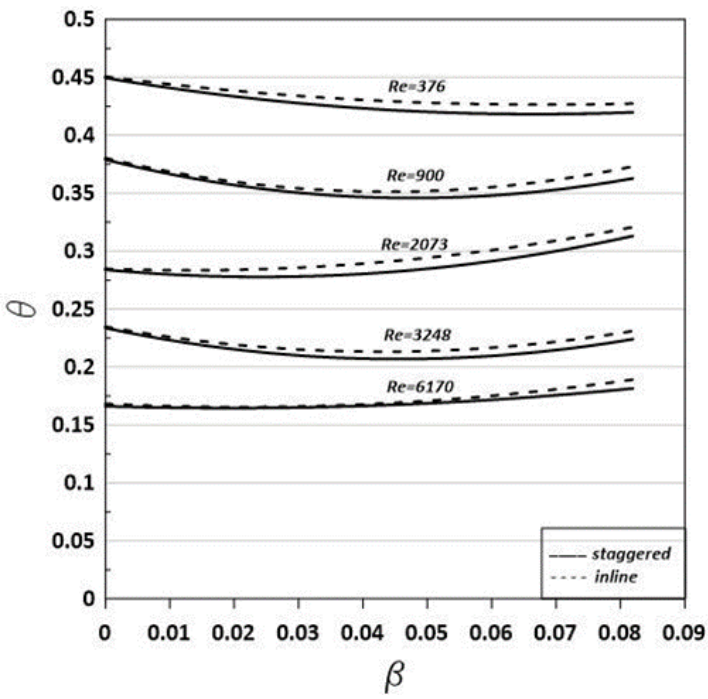

Fig. 15 Dimensionless temperature of third heater variation with open hole ratio for staggered and inline arrangements

and this is because the well distribution of air in the staggered arrangement than inline one.

As shown in Figs. 13-15, the dimensionless temperature distribution along the surfaces of the three heat sources in inline and staggered arrangements with different open hole ratios and Reynolds number range from 376 to 6170 .

As shown in Figs. 16-18, the average Nusselt number for the surfaces of the three heat sources in inline and staggered arrangements with different open hole ratios and Reynolds number range from 376 to 6170 .

The difference between inline and staggered arrangements in cooling heat sources has a tendency to neglect at high Reynolds number due to that the forced convection effect has the main effect in cooling at high velocity.

On the contrast of the dimensionless temperature, the Nusselt number increases gradually until it reaches to the peak

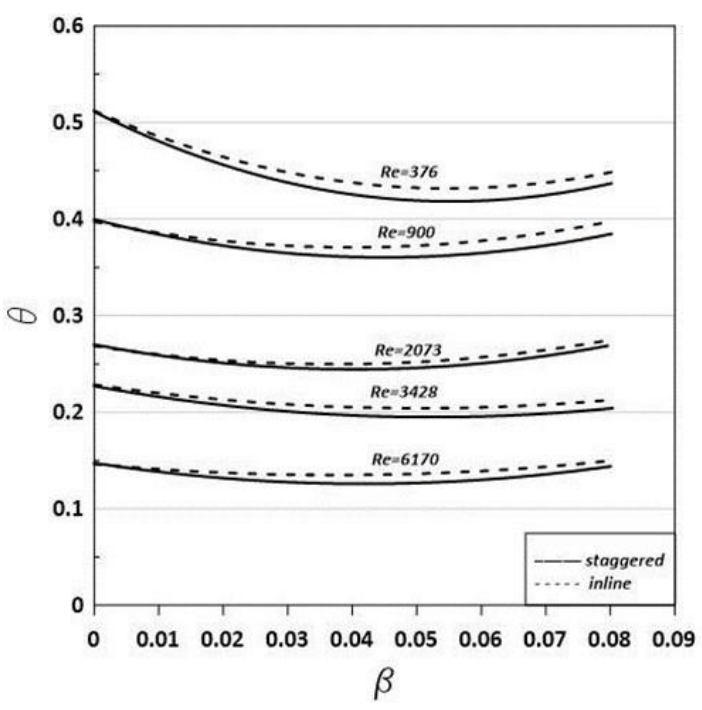

Fig. 14 Dimensionless temperature of second heater variation with open hole ratio for staggered and inline arrangements

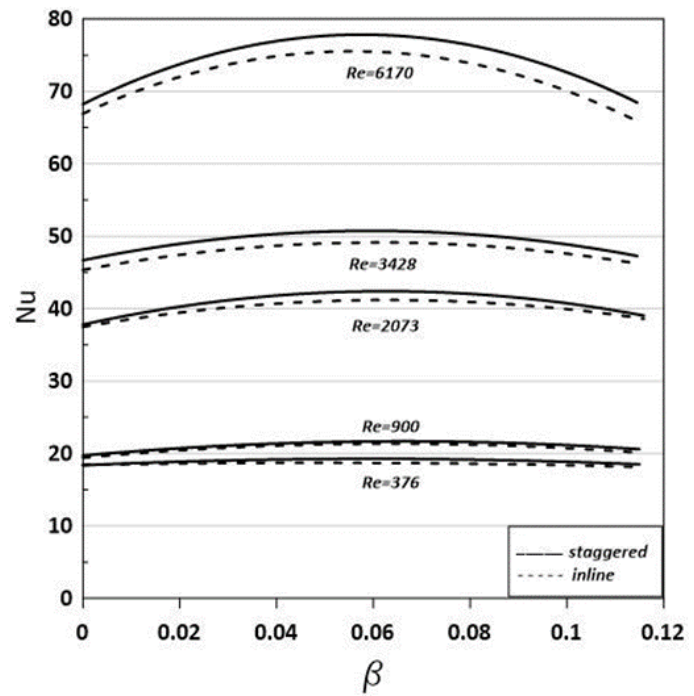

Fig. 16 Average Nusselt number of first heater variation with open hole ratio for staggered and inline arrangements

point at $2.5 \mathrm{~mm}$ diameter, then decreases for other design points.

Figure 19 shows the improvement of different holes variation with $\operatorname{Re}$ range (376 to 6170). The improvement increases gradually until the diameter hole is $2 \mathrm{~mm}$ then decreasing because the percentage of pressure drop increase is higher than the percentage of Nusselt increase.

Fig. 20 shows the velocity streamlines in staggered and inline arrangements for optimized design $d=2.5 \mathrm{~mm}$ and no holes at $\operatorname{Re}=376$ as an example for the buoyancy effect and well distributed air in the case of staggered arrangement.

Fig. 21 shows the temperature contours for no holes and Fig. 22 shows the temperature contours in staggered and inline arrangements with different diameter holes $d=(1.5 \mathrm{~mm}, 2 \mathrm{~mm}$, $2.5 \mathrm{~mm}, 3 \mathrm{~mm}, 3.5 \mathrm{~mm}$ ) at $\mathrm{Re}=376$. 


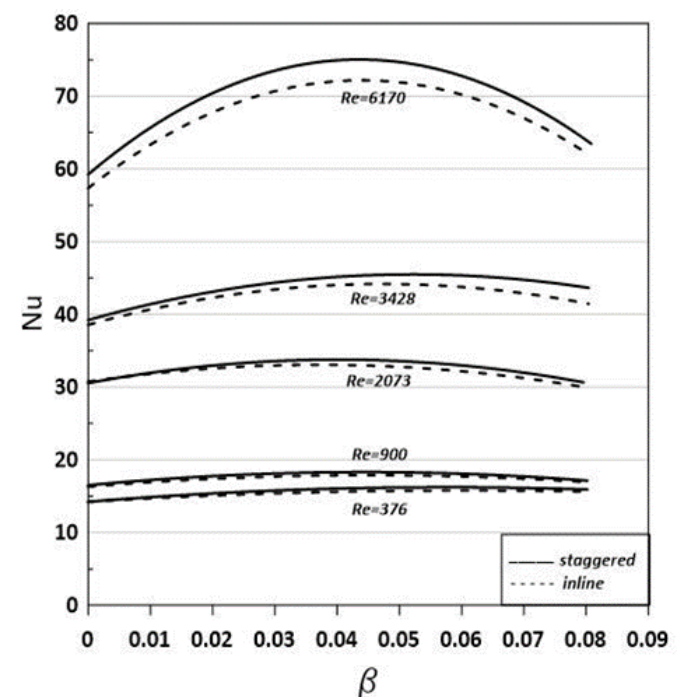

Fig. 17 Average Nusselt number of second heater variation with open hole ratio for staggered and inline arrangements

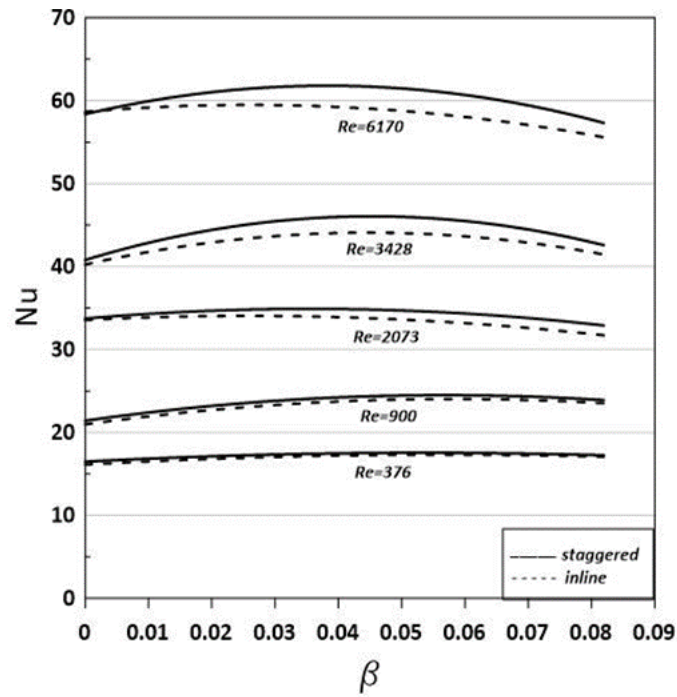

Fig. 18 Average Nusselt number of third heater variation with open hole ratio for staggered and inline arrangements

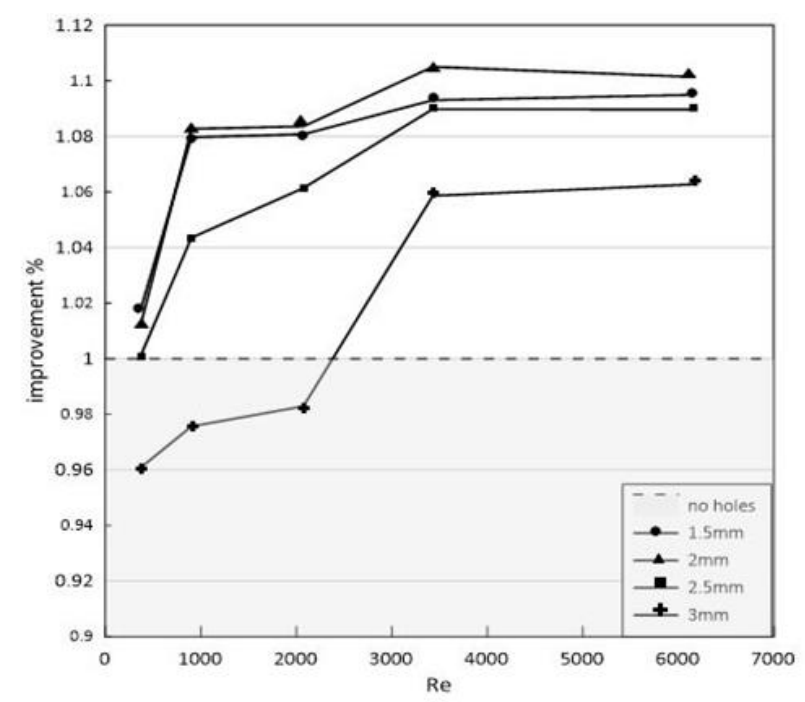

Fig. 19 Improvement of different holes variation with Reynolds number

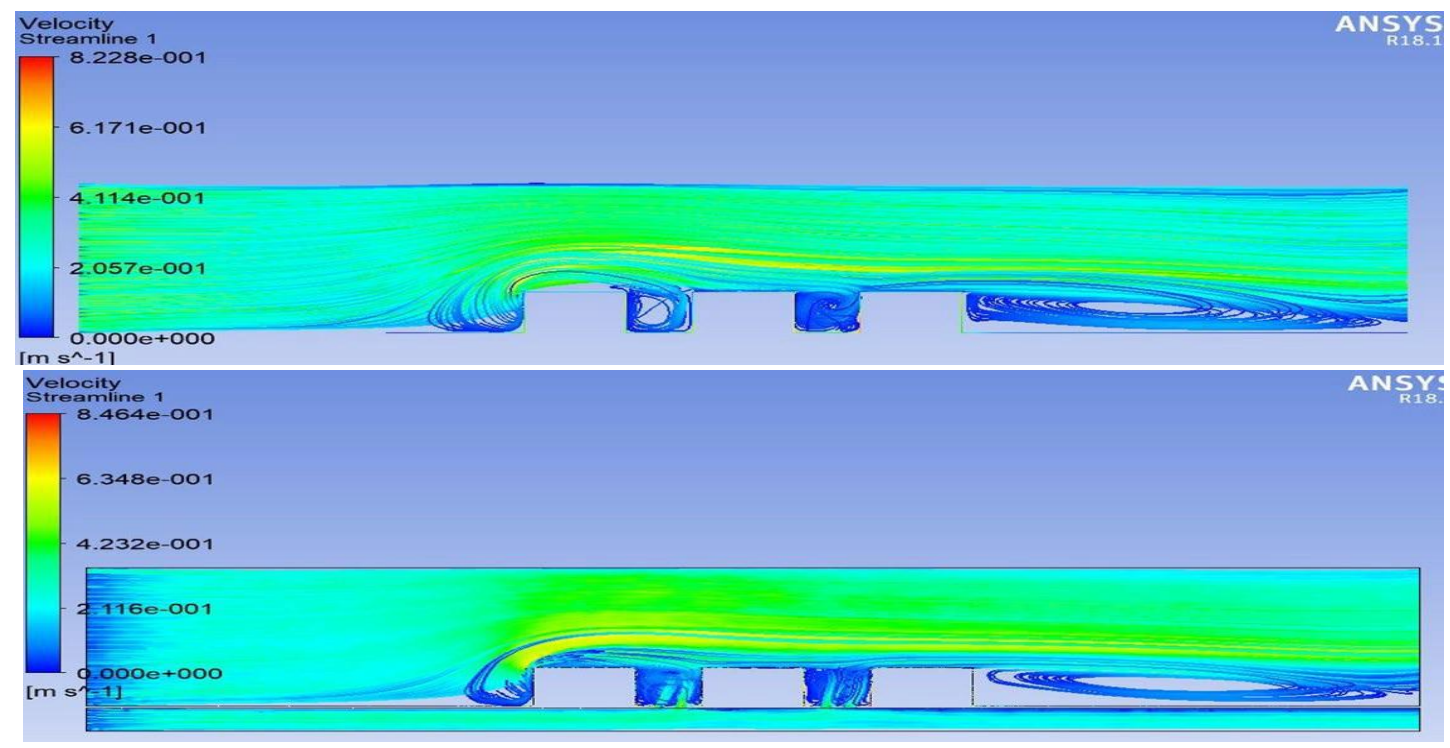

Fig. 20 Velocity streamlines for no holes and $2.5 \mathrm{~mm}$ hole diameter 


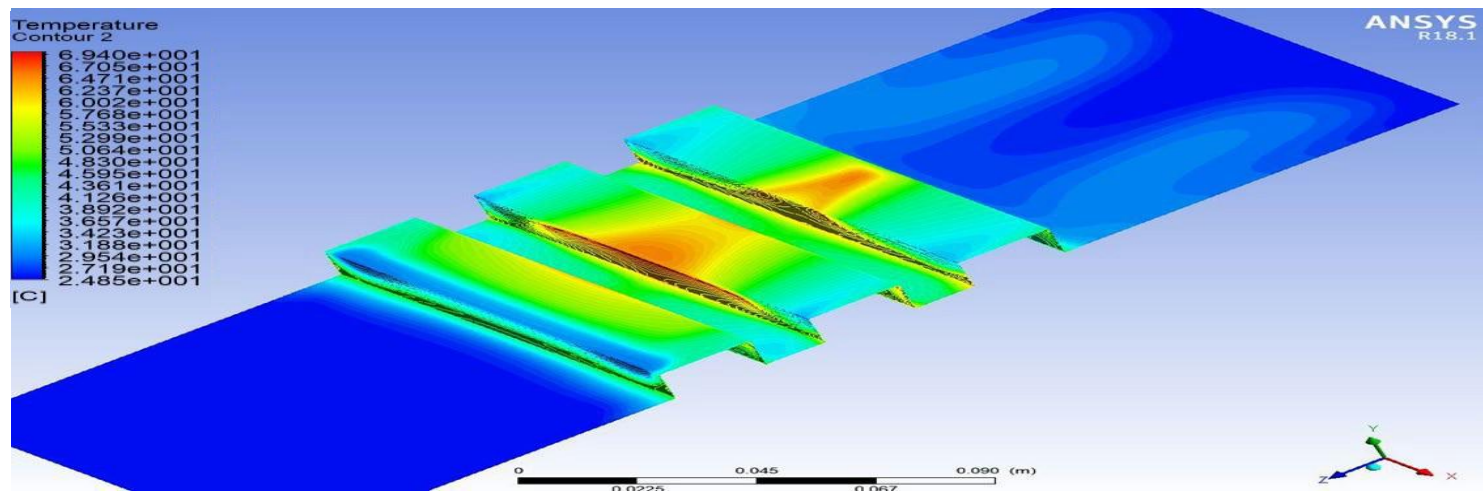

Fig. 21 Temperature contours for no holes at $\mathrm{Re}=376$

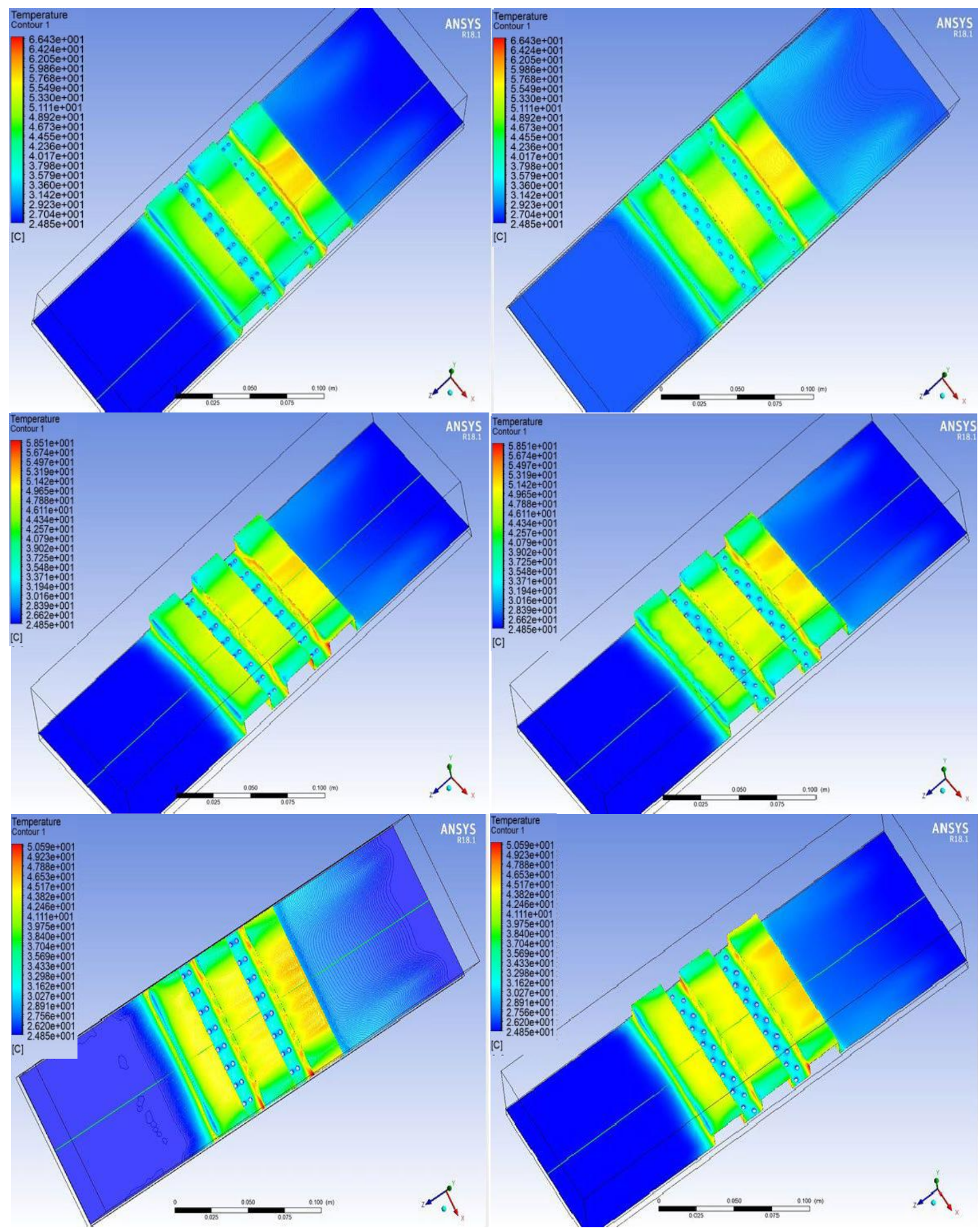



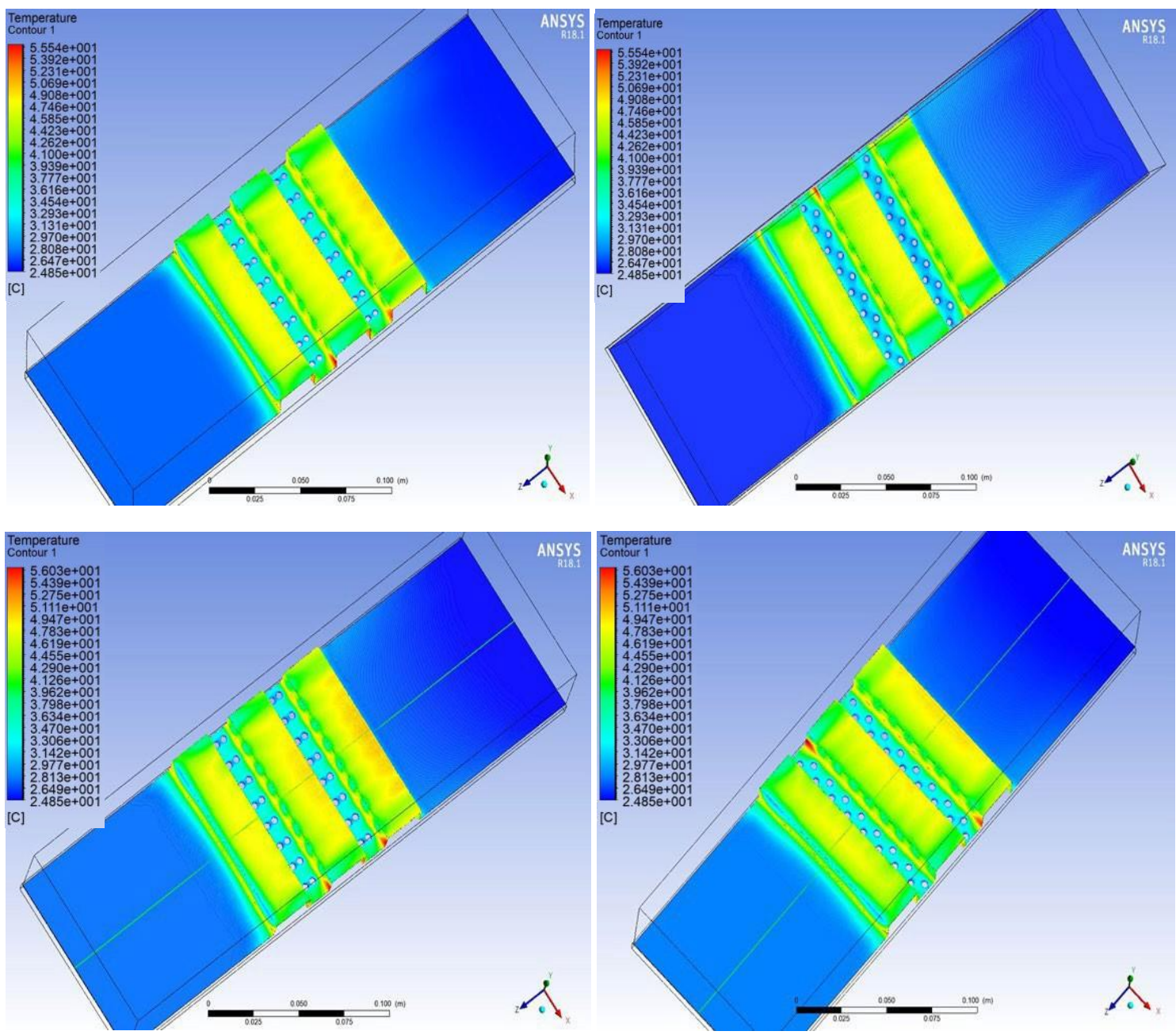

Fig. 22 Temperature contours for inline and staggered arrangements with different open hole ratios at $\mathrm{Re}=376$

\section{CONCLUSION}

The results of this study show the effect of the holes in the duct for increasing cooling of the heat sources and these results can be introduced as follows:

1. The perforated holes between heat sources can decrease the dimensionless temperature by $5 \%$ for the first heater, $15 \%$ for the second heater, and $6 \%$ for the third heater at $\operatorname{Re}=376$, these percentages decrease gradually with increasing the Reynolds number.

2. The dimensionless temperature of the second heater is larger than other heaters at $\mathrm{Re}=376$ (low Reynolds number) but at $\mathrm{Re}=6170$, the dimensionless temperature of third heater is larger.

3. Enhancement of cooling heat sources increases with increasing the diameter of the hole until certain value and the best performance is at $d=2.5 \mathrm{~mm}$.

4. The staggered arrangement gives performance better than inline one in cooling heat sources.

5. The effect of the arrangement can be neglected at high Reynolds number $(\mathrm{Re}>6170)$.

6. The maximum enhancement percentage in average Nusselt number is about $25 \%$ at $d=2.5 \mathrm{~mm}$.

\section{REFERENCES}

[1] F.P. Incropera, Electronic heat transfer for electronic equipment cooling. ASME Journal of Heat Transfer, 110: 1097-1111, 1998.

[2] S.W. Chang, T.M. Liou, R.F. Chiang, and G.F. Hong. Heat transfer and pressure drop in rectangular channel with compound roughness of Vshaped ribs and deepened scales. International Journal of Heat and Mass Transfer, 51(3-4): 457-468, 2008.

[3] J.M. Buchlin, Convective heat transfer in a channel with perforated ribs. International Journal of Thermal Sciences, 41(4): 332-340, 2002.

[4] P.R. Chandra, C.R. Alexander, and J.C. Han, Heat transfer and friction behaviors in rectangular channels with varying number of ribbed walls. International Journal of Heat and Mass Transfer, 46(3): 481-495, 2003.

[5] S.C. Lau, J. Cervantes, J.C. Han, R.J. Rudolph, and K. Flannery, Measurements of wall heat (mass) transfer for flow through blockages with round and square holes in a wide rectangular channel. International Journal of Heat and Mass Transfer, 46(21): 3991-4001, 2003.

[6] O.N. Sara, T. Pekdemir, S. Yapici, and M. Yilmaz, Heat-transfer enhancement in a channel flow with perforated rectangular blocks. International Journal of Heat and Fluid Flow, 22(5): 509-518, 2001.

[7] P. Dutta and A. Hossain, Internal cooling augmentation in rectangular channel using two inclined baffles. International Journal of Heat and Fluid Flow, 26(2): 223-232, 2004.

[8] G.I. Sultan, Enhancing forced convection heat transfer from multiple protruding heat sources simulating electronic components in a horizontal channel by passive cooling. Microelectronics Journal, 31(9-10): 773779, 2000.

[9] R.K. Ali, Heat transfer enhancement from protruding heat sources using perforated zone between the heat sources. Applied Thermal Engineering, 29(13): 2766-2772, 2009.

[10] R.K. Ali, H.A. Refaey, and M.R. Salem, Effect of package spacing on 
convective heat transfer from thermal sources mounted on a horizontal plate. Applied Thermal Engineering, 132: 676-685, 2018.

[11] B. Ghasemi and S.M. Aminossadati, Numerical simulation of mixed convection in a rectangular enclosure with different numbers and arrangements of discrete heat sources. Arabian Journal for Science and Engineering, 33: 189-207, April 2008.

[12] T.A. Alves and C.A.C. Altemani, Convective cooling of three discrete heat sources in channel flow. Journal of the Brazilian Society of Mechanical Sciences and Engineering, 30(3): 245-252, 2008.

[13] M. El Nakla, Forced convection heat transfer in two-dimensional ribbed channels with varying heat flux profiles using ANSYS software and modeling. Arabian Journal for Science and Engineering, 39(3): 21572164,2014

[14] Y. Zeng and K. Vafai, An investigation of convective cooling of an array of channel-mounted obstacles. Numerical Heat Transfer, Part A: Applications, 55(11): 967-982, 2009

[15] E. Jassim and Y.S. Muzychka, Optimal distribution of heat sources in convergent channels cooled by laminar forced convection. Journal of Heat Transfer, 132(1): p. 011701, 2010.

[16] V.K. Mathew and T.K. Hotta, Experimental investigation of substrate board orientation effect on the optimal distribution of IC chips under forced convection. Experimental Heat Transfer, 1-22, 2020.

[17] A.K. da Silva, S. Lorente, and A. Bejan, Optimal distribution of discrete heat sources on a plate with laminar forced convection. International Journal of Heat and Mass Transfer, 47: 2139-2148, 2004.

[18] A. Alamgholilou and E. Esmaeilzadeh, Experimental investigation on hydrodynamics and heat transfer of fluid flow into channel for cooling of rectangular ribs by passive and EHD active enhancement methods. Experimental Thermal and Fluid Science, 38: 61-73, 2012.

[19] B.A. Jubran and M.S. Al-Haroun, Heat transfer enhancement in electronic modules using various secondary air injection hole arrangements. Journal of Heat Transfer, 120(2): 342-347, 1998.

[20] Y.P. Cheng, T.S. Lee, and H.T. Low, Numerical simulation of conjugate heat transfer in electronic cooling and analysis based on field synergy principle. Applied Thermal Engineering, 28(14-15): 1826-1833, 2008

[21] Q.H. Deng, G.F. Tang, Y. Li, and M.Y. Ha, Interaction between discrete heat sources in horizontal natural convection enclosures. International Journal of Heat and Mass Transfer, 45(26): 5117-5132, 2002.

\section{Title Arabic:}
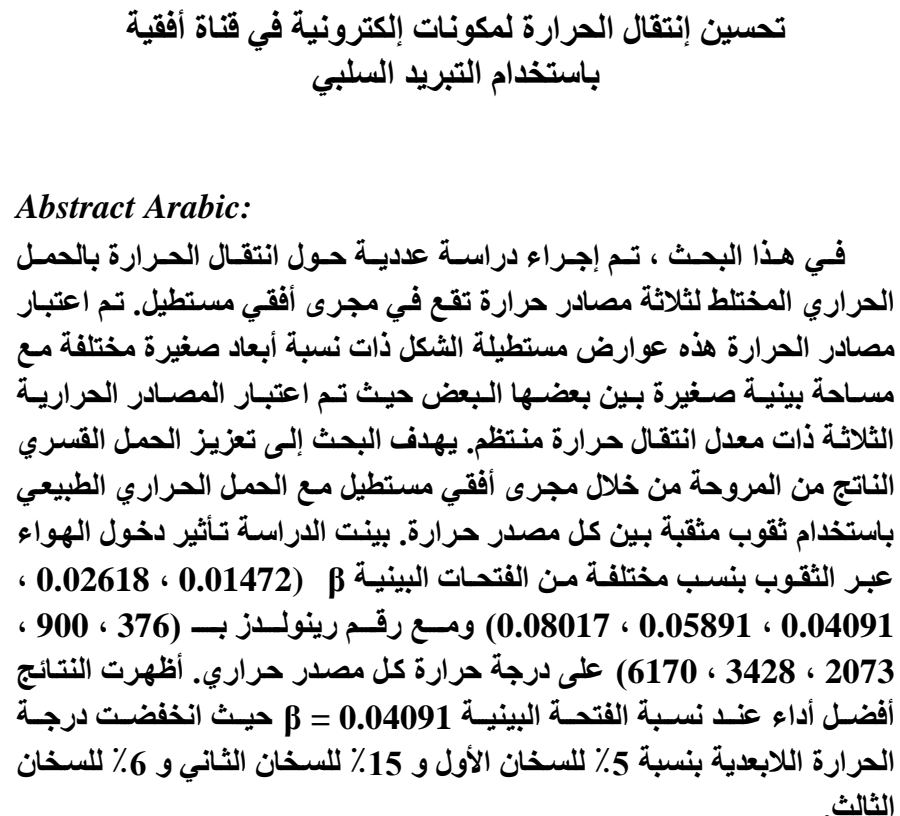

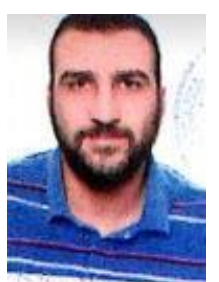

M.I. Salem, B.Sc. in Mechanical Power Engineering, "Very Good with Honor" Grade: 80.73\%. Graduation Project: Pressurized water reactor "Excellent grade" 2016. Teaching Assistant at Borg El-Arab Institute of Engineering and Technology (8 months) for the courses: Mathematics, Mechanics, Theory of Machines, Thermodynamics - Fundamentals. HS Engineers Institute of Engineering in Kuwait (3 months): Heat Transfer (Heat Transfer: A Practical Approach, edition 8 by Yunus Cengel) Thermodynamics (Thermodynamics: An Engineering Approach, edition 8 by Yunus Cengel). Teaching at Future Institute (from 2018-until now) for the courses: Thermodynamics, Mechanics, Fluid Mechanics, Refrigeration and Air Conditioning.

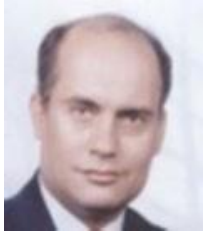

G.I. Sultan, B.Sc., Mechanical Power Engineering Dept., Faculty of Engineering, Mansoura University, Mansoura, Egypt, 1980, Very Good Honor. M.Sc., Mechanical Power Engineering Dept., Mansoura University, Mansoura, Egypt, 1985. Ph.D., Mechanical Power Engineering Dept., Faculty of Engineering, Mansoura University, Mansoura, Egypt, 1994. From (1994-2003) Assistant Professor, Mechanical Power Engineering Dept., Mansoura University, Egypt. From (2003-2008) Associate Professor, Mechanical Power Engineering Dept., Faculty of Engineering, Mansoura University, Mansoura, Egypt. From (2008-until now) Professor, Mechanical Power Engineering Dept., Faculty of Engineering, Mansoura University, Mansoura. Most important publication papers: "Experimental heat transfer from heating source subjected to rigorous natural convection inside enclosure and cooled by forced nanofluid flow", "Enhancement of a solar still performance by inclusion the basalt stones as a porous sensible absorber: Experimental study and thermo-economic analysis", "Augmented heat and mass transfer on the performance of a solar still using porous absorber: Experimental investigation and exegetic analysis", "Thermal and hydraulic analysis for air flow across flat tubes air cooled condensers".

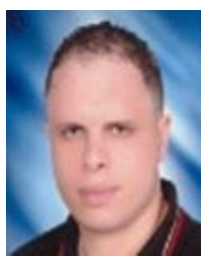

A.A. Hegazi, B.Sc., Mechanical Power Engineering Dept., Faculty of Engineering, Mansoura University, Mansoura, Egypt, 1999, Very Good Honor. M.Sc., Mechanical Power Engineering Dept., Mansoura University, Mansoura, Egypt, 2003. Ph.D., Mechanical Power Engineering Dept., Faculty of Engineering, Mansoura University, Mansoura, Egypt, 2011. From (1999-2003) Teaching Assistant, Mechanical Power Engineering Dept., Mansoura University, Egypt. From (2003-2011) Assistant Lecturer, Mechanical Engineering Dept., Faculty of Engineering, Mansoura University, Mansoura, Egypt. From (2011-2019) Assistant Professor, Mechanical Power Engineering Dept., Faculty of Engineering, Mansoura University, Mansoura, and from (2019-until now) Associate Professor. Most important publication papers: "An experimental study of thermal performance of an organic two-phase closed thermo syphon in waste heat extraction", "Experimental study of jet impinging double-pass solar air heater using wire-mesh", "An investigation on drying process in a novel configuration of fluidized bed".

Waleed M. ElAwady, B.Sc., Mechanical Power Engineering Dept., Faculty

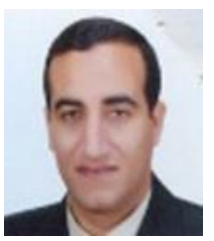
of Engineering, Mansoura University, Mansoura, Egypt, 2000, Very Good Honor. M.Sc., Mechanical Power Engineering Dept., Mansoura University, Mansoura, Egypt, 2006. Ph.D., Mechanical Power Engineering Dept., Faculty of Engineering, Mansoura University, Mansoura, Egypt, 2012. From (2001-2006) Teaching Assistant, Mechanical Power Engineering Dept., Mansoura University, Egypt. From (2006-2012) Assistant Lecturer, Mechanical Engineering Dept. Faculty of Engineering, Mansoura University, Mansoura, Egypt. From (2012-until now) Assistant Professor, Mechanical Power Engineering Dept., Faculty of Engineering, Mansoura University, Mansoura. Most important publication papers: "Thermodynamic properties of 1-butyl-3-methylpyridinium tetrafluoroborate", "Thermophysical properties of 1-Butyl-4-methylpyridinium tetrafluoroborate", "A novel approach for enhancing the utilization of solid desiccants in packed bed via intercooling". 